\title{
Article \\ Intracellular Exposure Dose-Associated Susceptibility of Steatotic Hepatocytes to Metallic Nanoparticles
}

\author{
Xiaoli Zhang ${ }^{1}$, Yongyi Wei ${ }^{2}$, Chengjun $\mathrm{Li}^{1}{ }^{\text {, Weiyu Wang }}{ }^{1}$, Rui Zhang ${ }^{1}$, Jianbo Jia ${ }^{1, *}$ and Bing Yan ${ }^{1,2}$ \\ 1 Key Laboratory for Water Quality and Conservation of the Pearl River Delta, Ministry of Education, \\ Institute of Environmental Research at Greater Bay Area, Guangzhou University, Guangzhou 510006, China; \\ xiaoli_Zhang19@163.com (X.Z.); cli@gzhu.edu.cn (C.L.); wangweiyu2020@126.com (W.W.); \\ zhangrui20201001@163.com (R.Z.); drbingyan@yahoo.com (B.Y.) \\ 2 School of Environmental Science and Engineering, Shandong University, Qingdao 266237, China; \\ weiyy1991@163.com \\ * Correspondence: jb_jia@gzhu.edu.cn; Tel.: +86-20-3714-2113
}

Citation: Zhang, X.; Wei, Y.; Li, C.; Wang, W.; Zhang, R.; Jia, J.; Yan, B. Intracellular Exposure

Dose-Associated Susceptibility of Steatotic Hepatocytes to Metallic Nanoparticles. Int. J. Mol. Sci. 2021, 22, 12643. https://doi.org/ 10.3390/ijms222312643

Academic Editor: Alberto Cuesta

Received: 10 November 2021

Accepted: 21 November 2021

Published: 23 November 2021

Publisher's Note: MDPI stays neutral with regard to jurisdictional claims in published maps and institutional affiliations.

Copyright: () 2021 by the authors. Licensee MDPI, Basel, Switzerland. This article is an open access article distributed under the terms and conditions of the Creative Commons Attribution (CC BY) license (https:// creativecommons.org/licenses/by/ $4.0 /)$.

\begin{abstract}
Non-alcoholic fatty liver disease (NAFLD), mainly characterized by the accumulation of excess fat in hepatocytes, is the most prevalent liver disorder afflicting $\sim 25 \%$ of adults worldwide. In vivo studies have shown that adult rodents with NAFLD were more sensitive to metallic nanoparticles (MNPs) than healthy MNPs. However, due to the complex interactions between various cell types in a fatty liver, it has become a major challenge to reveal the toxic effects of MNPs to specific types of liver cells such as steatotic hepatocytes. In this study, we reported the susceptibility of steatotic hepatocytes in cytotoxicity and the induction of oxidative stress to direct exposures to MNPs with different components (silver, $\mathrm{ZrO}_{2}$, and $\mathrm{TiO}_{2} \mathrm{NPs}$ ) and sizes $(20-30 \mathrm{~nm}$ and $125 \mathrm{~nm}$ ) in an oleic acid (OA) -induced steatotic HepG2 (sHepG2) cell model. Furthermore, the inhibitory potential of MNPs against the process of fatty acid oxidation (FAO) were obvious in sHepG2 cells, even at extremely low doses of 2 or $4 \mu \mathrm{g} / \mathrm{mL}$, which was not observed in non-steatotic HepG2 (nHepG2) cells. Further experiments on the differential cell uptake of MNPs in nHepG2 and sHepG2 cells demonstrated that the susceptibility of steatotic hepatocytes to MNP exposures was in association with the higher cellular accumulation of MNPs. Overall, our study demonstrated that it is necessary and urgent to take the intracellular exposure dose into consideration when assessing the potential toxicity of environmentally exposed MNPs.
\end{abstract}

Keywords: susceptible population; nanotoxicity; steatotic hepatocytes; lipid metabolism; intracellular exposure dose

\section{Introduction}

The widespread applications of nanomaterials in various areas such as consumer products [1], agriculture [2], biomedicine [3] and environmental remediation [4] result in their higher environmental release and human exposure. Metallic nanoparticles (MNPs) are among the largest classes of engineered nanoparticles (NPs) found in daily life. For example, commercial products containing MNPs account for $70 \%$ of the listed entries with identified NPs supplemented [5]. Environmentally exposed MNPs may enter the human body, interact with biomolecules, and perturb various physiological systems [6,7]. Such adverse outcomes in response to MNP exposure may be further aggravated in susceptible populations characterized by underdeveloped protection mechanisms, impaired self-repair ability, and/or compromised immunity [8-10]. Therefore, it is urgent to reveal the potential toxic effects of engineered MNPs to various susceptible populations.

The liver is the main target of various xenobiotic substances including MNPs [11]. Individuals with hepatic disorders (e.g., hepatitis [12] and hepatic steatosis [13]) are, thus, suggested to be more sensitive to environmentally exposed MNPs. Non-alcoholic fatty liver disease (NAFLD) is the most prevalent liver disorder characterized by excess accumulation 
of fat in hepatocytes, afflicting approximately $25 \%$ of the global adult population [14,15]. Exposure to MNPs resulted in aggravated liver injuries in animal models of NAFLD, with enhanced hepatic inflammation and hepatocyte steatosis as the major manifestations [13,16-19]. However, the complex interplay among different kinds of liver cells in animals has become a limitation for exploring the direct toxic effects of MNPs to the specific type of liver cells.

Hepatocytes are the major parenchymal cells of the liver, comprising $70-85 \%$ of liver volume and playing critical roles in metabolism, detoxification, protein synthesis, and innate immunity [20]. In vitro studies showed that exposure to MNPs led to oxidative stress, inflammation, and eventually different types of cell death outcomes in various hepatic cell lines [21]. While the different sensitivities of normal liver cells and hepatic cancer cells to MNP exposure have been reported in several recent studies, with cancer cells more sensitive than normal cells $[22,23]$, the susceptibility of hepatocytes with physiological abnormalities, i.e., steatotic hepatocytes, to direct MNP exposure, remains to be elucidated.

The oleic acid (OA)-induced steatotic HepG2 cell model shows morphological similarities to the hepatocytes of patients with hepatic steatosis and, thus, has been applied as an in vitro model of steatosis for revealing pathogenesis and evaluating the effects of medical or dietary interventions of hepatic steatosis [24-26]. In the present study, the toxic potential of several MNPs with high environmental exposure risks to human non-steatotic and steatotic hepatocytes was determined. Both composition and particle size are critical factors in determining the cytotoxicity of MNPs [27,28]. While silver nanoparticles (Ag $\mathrm{NPs}$ ) and titanium dioxide NPs $\left(\mathrm{TiO}_{2} \mathrm{NPs}\right.$ ) are the top two MNPs that have the most prevalent usage in consumer products [5], zirconium dioxide $\mathrm{NPs}\left(\mathrm{ZrO}_{2} \mathrm{NPs}\right)$ have been widely used for the removal of various pollutants from wastewater, environmental water, and even drinking water $[29,30]$. Thus, four NPs that have distinct compositions and/or particle sizes were selected to reveal the differential toxicity of MNPs to non-steatotic and steatotic hepatocytes.

\section{Results}

\subsection{Characterization of MNPS}

All four MNPs selected were spherical in shape, with transmission electron microscope (TEM) sizes of $23.58 \pm 6.30,28.15 \pm 6.31,21.16 \pm 5.04$, and $125.28 \pm 41.16 \mathrm{~nm}$ for Ag NPs, $\mathrm{ZrO}_{2} \mathrm{NPs}$, small-sized $\mathrm{TiO}_{2}\left(\mathrm{sTiO}_{2}\right) \mathrm{NPs}$, and large-sized $\mathrm{TiO}_{2}\left(\mathrm{lTiO}_{2}\right) \mathrm{NPs}$, respectively (Figure 1). The hydrodynamic diameters of these NPs were generally much larger than their TEM sizes, which were further enlarged in minimum essential medium (MEM) cell culture medium supplemented with $10 \%$ fetal bovine serum (FBS) due to the adsorption of proteins on the surface (Figure 1E). The formation of protein corona also shifted the surface charges, generally increasing the zeta potential values of these four NPs to similar levels (Figure 1E).

\subsection{Steatotic Hepatocyte Modeling}

The dose-dependent effects of OA treatments on the accumulation of lipid and growth of HepG2 cells were determined for the selection of a proper dose for steatotic hepatocyte modeling. There was almost an absence of intracellular lipid in cells without the treatment of OA (Figure 2A). OA treatments led to the accumulation of lipid droplets in the cytoplasm of HepG2 cells (Figure 2B-F), at a concentration of $\geq 0.5 \mathrm{mM}$. While treatments with 0.1 or $0.5 \mathrm{mM}$ OA showed little effect on the growth of cells, OA exposure at concentrations higher than $1.0 \mathrm{mM}$ resulted in a decreased cell index, suggesting significant alteration of cell growth (Figure 2G). Thus, an OA dose of $0.5 \mathrm{mM}$, which effectively induced steatosis without affecting the normal growth of HepG2 cells, was selected for steatotic hepatocyte modeling in the following experiments. Following steatotic hepatocyte modeling, the question of whether steatotic hepatocytes were more susceptible to MNP exposure was further investigated. 

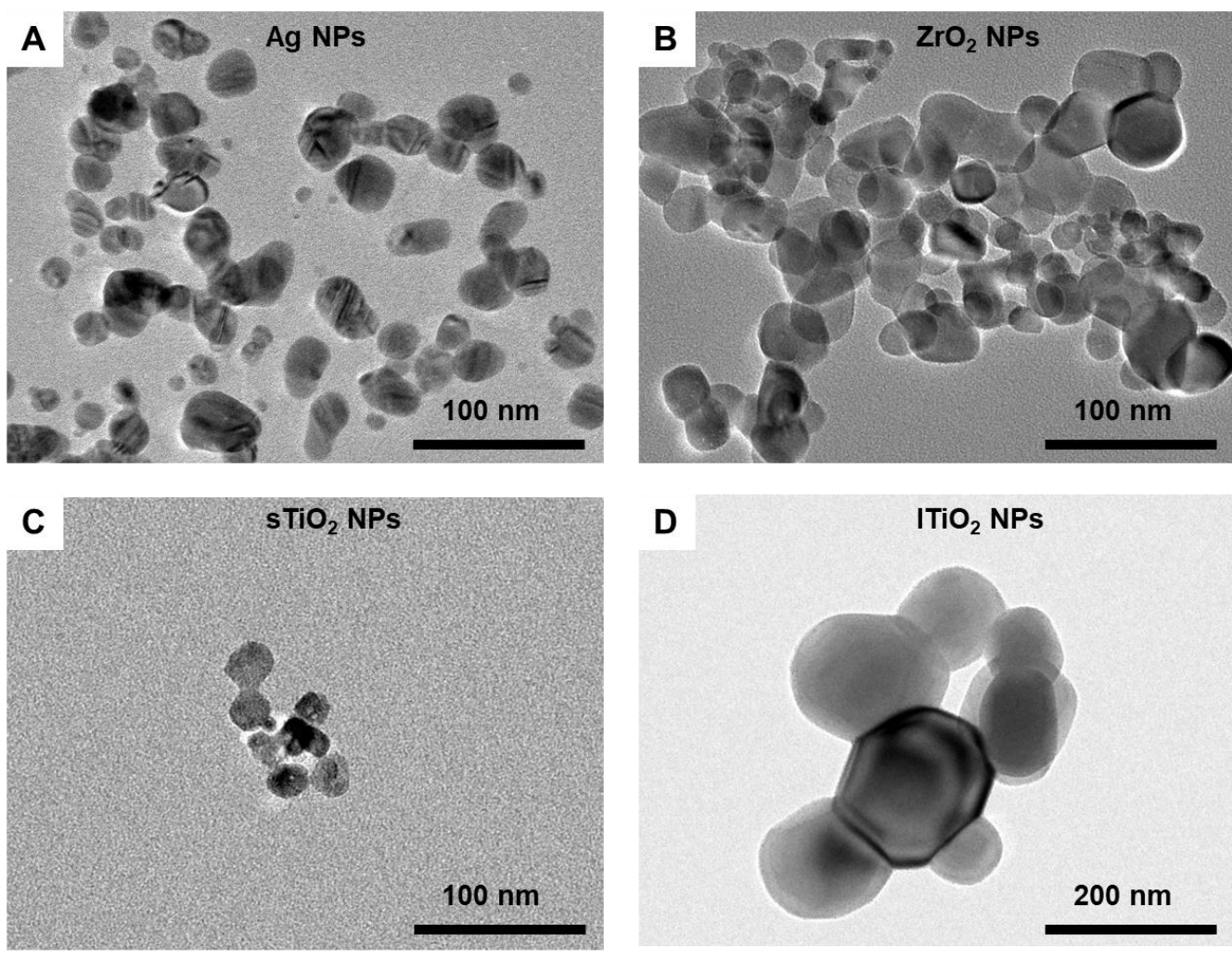

\begin{tabular}{llllll}
\hline $\mathbf{E}$ & & Ag NPs & $\mathbf{Z r O}_{2} \mathbf{N P s}$ & $\mathbf{s T i O}_{2} \mathbf{N P s}$ & $\mathbf{I T i O}_{2} \mathbf{N P s}$ \\
\hline TEM size $(\mathrm{nm})$ & & $23.58 \pm 6.30$ & $28.15 \pm 6.31$ & $21.16 \pm 5.04$ & $125.28 \pm 41.16$ \\
\hline Hydrodynamic & Water & $55.36 \pm 8.28$ & $31.11 \pm 2.53$ & $54.21 \pm 1.93$ & $256.36 \pm 7.52$ \\
diameter $(\mathrm{nm})$ & MEM & $127.42 \pm 6.53$ & $41.43 \pm 1.13$ & $66.52 \pm 2.41$ & $292.2 \pm 16.46$ \\
Zeta potential & Water & $-30.04 \pm 3.95$ & $-34.88 \pm 4.89$ & $-38.83 \pm 5.86$ & $-41.29 \pm 5.78$ \\
$(\mathrm{mV})$ & MEM & $-15.39 \pm 0.26$ & $-22.42 \pm 4.72$ & $-19.22 \pm 2.90$ & $-16.65 \pm 3.86$ \\
\hline
\end{tabular}

Figure 1. Characterization of MNPs. (A-D) TEM graphs of Ag NPs (A), $\mathrm{ZrO}_{2} \mathrm{NPs}(\mathbf{B})$, small-sized $\mathrm{TiO}_{2}\left(\mathrm{sTiO}_{2}\right) \mathrm{NPs}(\mathbf{C})$, and large-sized $\mathrm{TiO}_{2}\left(\mathrm{TiO}_{2}\right) \mathrm{NPs}(\mathbf{D})$. (E) Summarized characteristics of these four MNPs, including TEM size, hydrodynamic diameter, and zeta potential in DI water and MEM cell culture medium supplemented with $10 \%$ fetal bovine serum (FBS). In (E), data are shown as means \pm s.d., $\mathrm{n}=3$.

\subsection{Higher Cytotoxicity of MNPs to sHepG2 Than to nHepG2}

$\mathrm{Ag}$ NPs are the most toxic of the four MNPs, causing a decrease in viability of nonsteatotic HepG2 (nHepG2) cells at concentrations $\geq 10 \mu \mathrm{g} / \mathrm{mL}$ (Figure $3 \mathrm{~A}$ ). $\mathrm{ZrO}_{2} \mathrm{NPs}$ caused a slight decrease in viability of nHepG2 cells at concentrations of $200 \mu \mathrm{g} / \mathrm{mL}$ (Figure $3 \mathrm{~B}$ ), and $\mathrm{TiO}_{2} \mathrm{NPs}$ of any of these two sizes showed little effect on the viability of nHepG2 cells at concentrations of as high as $50 \mu \mathrm{g} / \mathrm{mL}$ (Figure 3C,D). These results indicated the NP composition-dependent cytotoxicity of MNPs, which has been well recognized in previous studies [31-33]. 

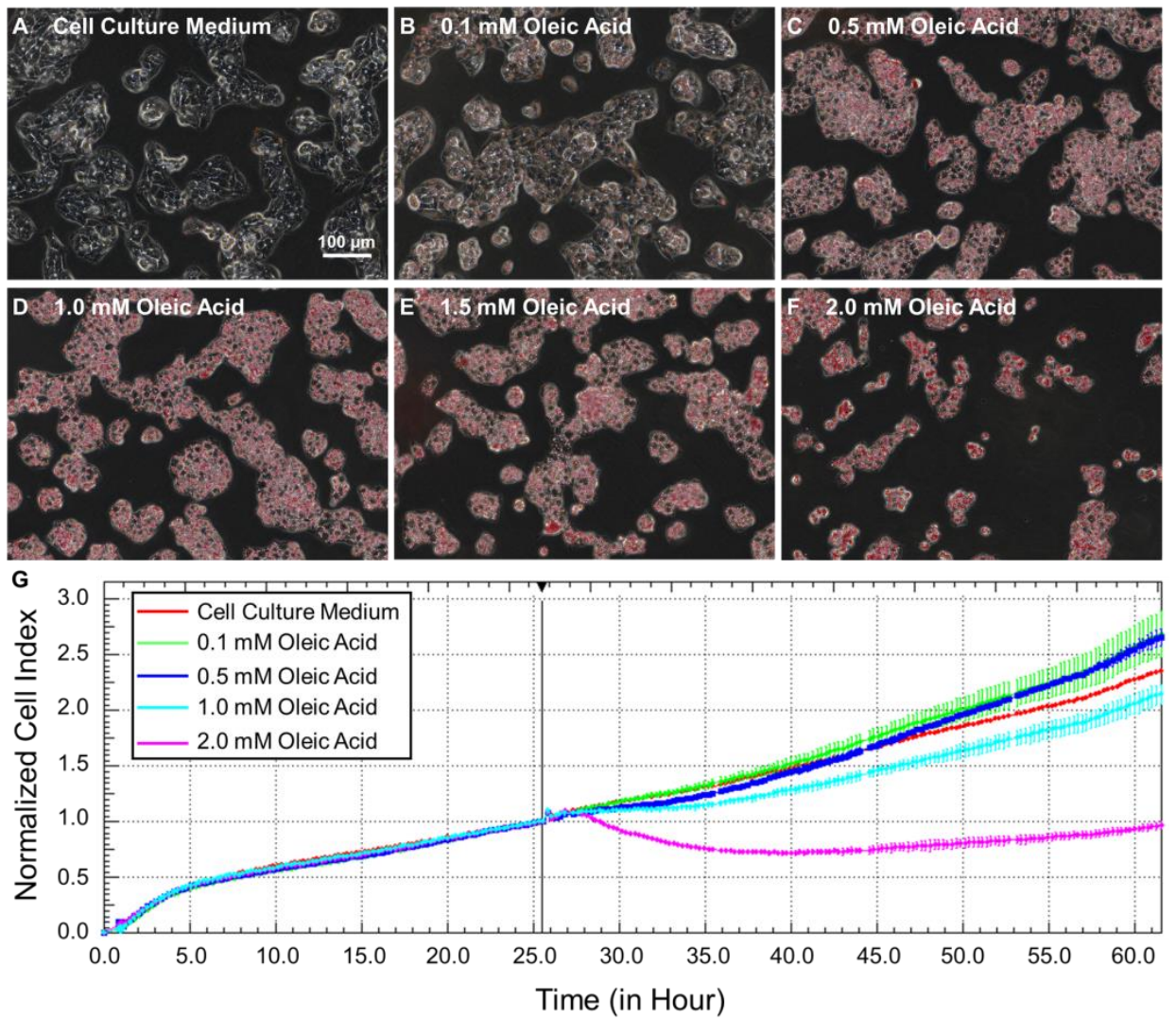

Figure 2. Steatotic hepatocyte modeling. (A-F) Micrograph of HepG2 cells with oil red O staining after $24 \mathrm{~h}$ treatments with OA of various concentrations. (G) Real-time growth status of HepG2 cells, as reflected by normalized cell index, in response to OA exposures.

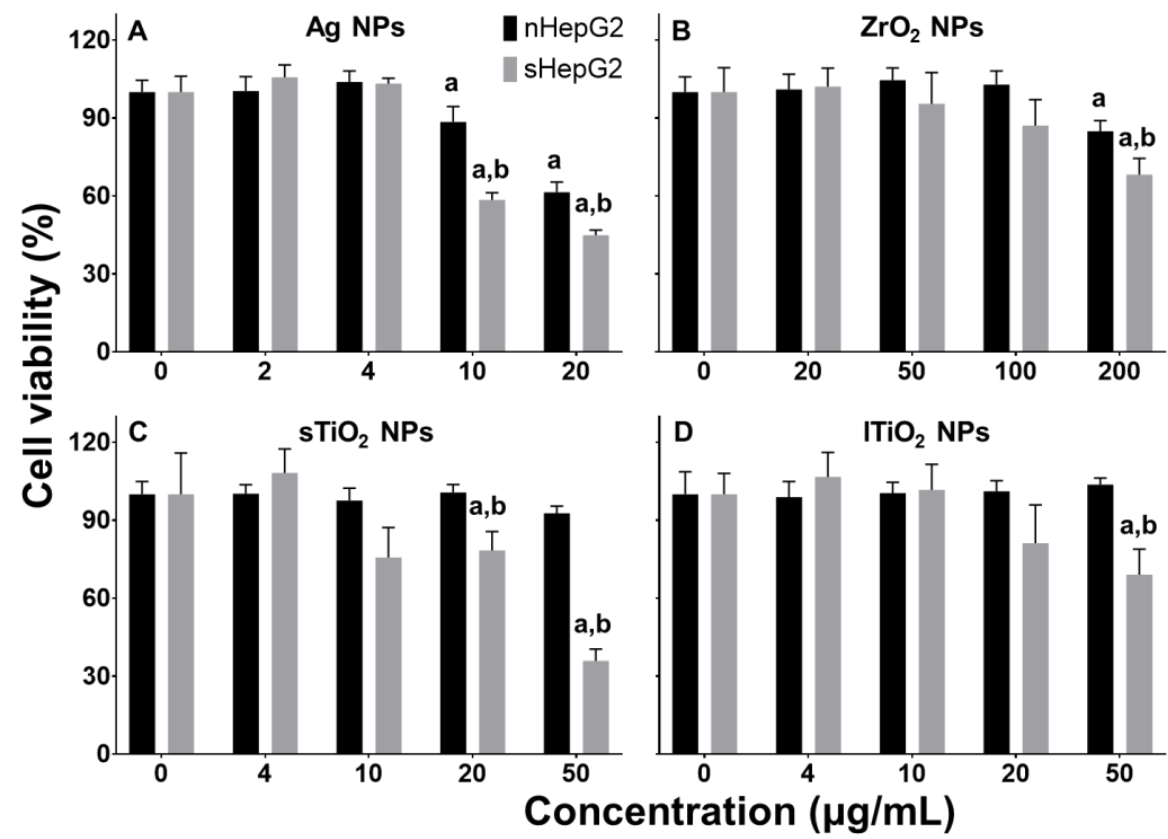

Figure 3. Susceptibility of steatotic hepatocytes to cytotoxicity in response to MNP exposures. (A-D) Dose-dependent viability of non-steatotic and steatotic HepG2 cells treated with Ag NPs (A), $\mathrm{ZrO}_{2}$ NPs (B), and $\mathrm{TiO}_{2}$ of different sizes $(\mathbf{C}, \mathbf{D})$. Data are shown as means \pm s.d., $\mathrm{n}=5 .{ }^{\mathrm{a}} p<0.05$, compared with vehicle control. ${ }^{\mathrm{b}} p<0.05$, compared with viability of nHepG2 cells with the same treatment. 
In steatotic HepG2 (sHepG2) cells, the toxicity of MNPs is much higher than that in nHepG2 cells. While the viabilities of nHepG2 cells treated with 10 and $20 \mu \mathrm{g} / \mathrm{mL}$ Ag NPs were $88.5 \%$ and $61.4 \%$, the same treatments reduced the viabilities of sHepG2 cells to $58.5 \%$ and $44.9 \%$, respectively (Figure $3 \mathrm{~A}$ ). In an OA-induced steatotic human hepatocellular carcinoma (HCC) Bel7402 cell model, Ag NP exposure also led to a much higher cytotoxicity than in the non-steatotic (Figure S1). Similar enhanced cytotoxicity to the steatotic hepatocytes, relative to the non-steatotic, was also found for $\mathrm{ZrO}_{2} \mathrm{NP}$ exposure, as indicated by a much lower cell viability of sHepG2 (68.2\%) compared with that of nHepG2 (84.9\%) in response to $200 \mu \mathrm{g} / \mathrm{mL} \mathrm{ZrO}_{2}$ NPs exposure (Figure 3B). Treatments with $50 \mu \mathrm{g} / \mathrm{mL} \mathrm{sTiO}$ and $1 \mathrm{TiO}_{2} \mathrm{NPs}$ decreased the cell viability to $35.9 \%$ and $69.0 \%$ only in sHepG2 cells (Figure 3C,D). Despite the similarity in cell type-, dose-, composition- and particle size-dependent cytotoxicity to non-steatotic and steatotic liver cells, our above results demonstrated that the steatotic hepatocytes were more susceptible in cytotoxicity to MNP exposure than the non-steatotic.

Using an antioxidant responsive element (ARE) reporter HepG2 cell line (as described in the Materials and Methods), we further investigated the ARE gene expression in nHepG2 and sHepG2 with NP treatments. Ag NPs and $\mathrm{sTiO}_{2} \mathrm{NPs}_{\mathrm{N}}$ showed little alteration on the expression of ARE reporter in nHepG2 cells, with the relative units ranging from $\sim 0.8$ to $\sim 1.0$ (Figure 4A). The ARE reporter expressions in sHepG2 cells exposed to 4, 8, or $12 \mu \mathrm{g} / \mathrm{mL} \mathrm{Ag} \mathrm{NPs} \mathrm{were} \mathrm{1.3-,} \mathrm{1.7-,} \mathrm{and} \mathrm{2.6-fold} \mathrm{that} \mathrm{of} \mathrm{vehicle} \mathrm{treatment} \mathrm{(Figure} \mathrm{4B).} \mathrm{Such}$ upregulated expressions of ARE reporter were much lower in $\mathrm{sTiO}_{2} \mathrm{NP}$ treated sHepG2 cells, with the relative units ranging from 1.2 to 1.4 (Figure 4B).
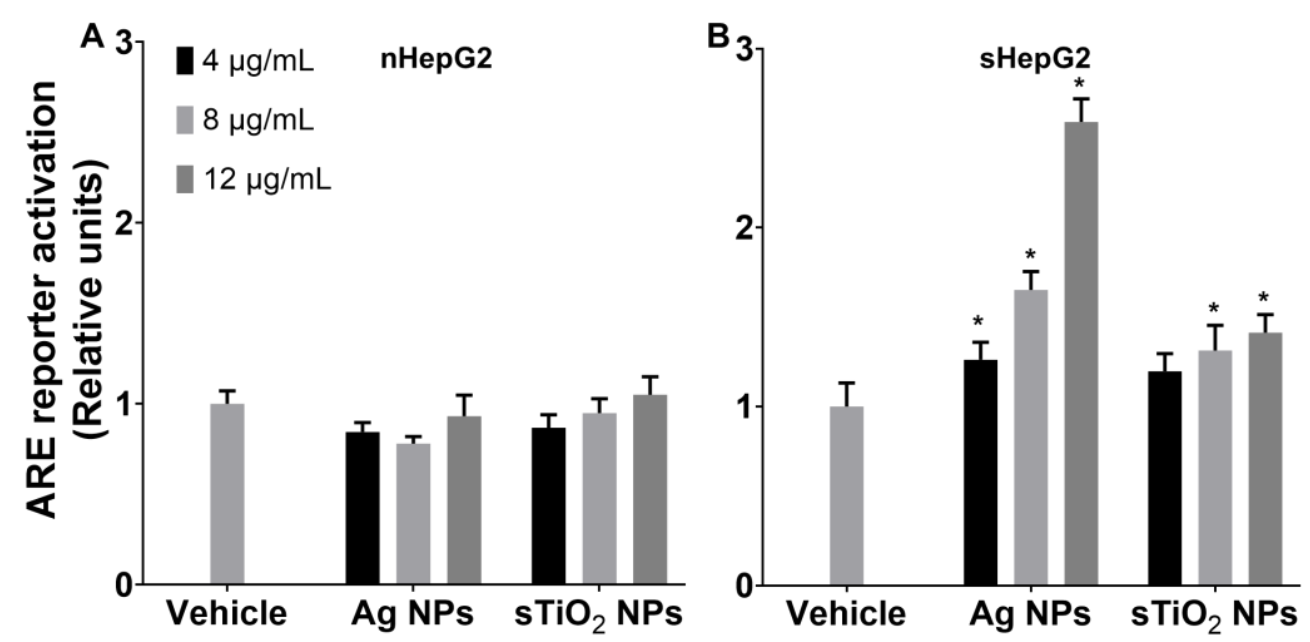

Figure 4. Upregulation of ARE reporter gene only in sHepG2 cells in response to NP exposure. $(\mathbf{A}, \mathbf{B})$ ARE reporter activation in $\mathrm{nHepG2}(\mathbf{A})$ and sHepG2 cells $(\mathbf{B})$ treated with $\mathrm{Ag} \mathrm{NPs}$ or $\mathrm{sTiO}_{2}$ NPs. Data are shown as means \pm s.d., $\mathrm{n}=5 .{ }^{*} p<0.05$, compared with vehicle control.

\subsection{Alterations of Fatty Acid Oxidation (FAO)-Related Genes in sHepG2 Cells}

The accumulation of lipid droplets in hepatocytes is one of the most basic pathological characteristics of clinical hepatic steatosis. Here, the alteration of NP exposures on the contents of intracellular lipids and the expression of lipid metabolism-related genes was further investigated. OA treatments led to lipid accumulation in cells and increased intracellular contents of both total cholesterol (T-CHO) and triacylglycerol (TG) (Figure 5). Exposure to MNPs caused few alterations in the intracellular lipids of either nHepG2 or sHepG2 cells (Figure 5). 

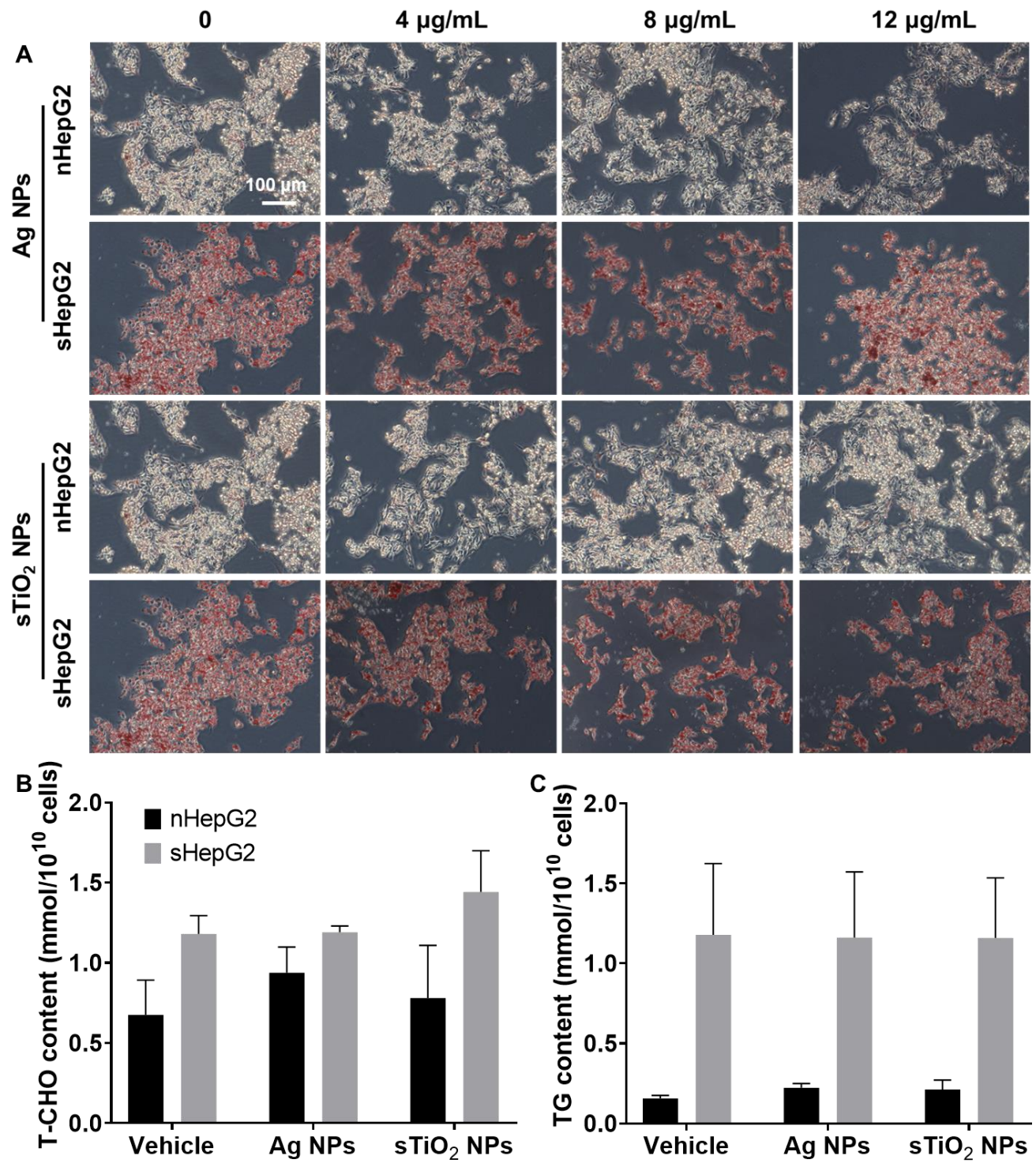

Figure 5. Qualitative and quantitative characterization of intracellular lipids in nHepG2 and sHepG2 cells after various treatments. (A) Micrograph of nHepG2 and sHepG2 cells with oil red O staining after $24 \mathrm{~h}$ treatments with $\mathrm{Ag}$ NPs or $\mathrm{sTiO}_{2}$ NPs. (B,C) Intracellular total cholesterol (T-CHO, (B)) and triacylglycerol (TG, (C)) contents in nHepG2 and sHepG2 cells treated with $4 \mu \mathrm{g} / \mathrm{mL}$ Ag NPs or $\mathrm{sTiO}_{2}$ NPs. In (B,C), data are shown as means \pm s.d., $\mathrm{n}=3$.

Despite the negative regulatory effects of MNPs on the intracellular lipids, the expression of several fatty acid metabolism-related genes was further detected in nHepG2 and sHepG2 cells in response to Ag NP exposure at non-lethal doses. The expressions of peroxisome proliferator activated receptor alpha (Ppara), peroxisome proliferator activated receptor delta (Ppard), peroxisome proliferator activated receptor gamma coactivator 1alpha $\left(P_{g c} 1 a\right)$, and carnitine palmitoyltransferase-1b $(C p t 1 b)$ in sHepG2 cells were 1.12-, 1.30-, 1.77-, and 2.09-fold those in nHepG2 (Figure 6), suggesting enhanced FAO in response to OA internalization in sHepG2 cells. While showing little alteration on the expressions of these four FAO-related genes in nHepG2 cells, Ag NPs exposure ( $4 \mu \mathrm{g} / \mathrm{mL}$ ) upregulated the expression of Ppard by $112 \%$ but downregulated the expression of its coactivator Pgc1a and target gene Cpt1b by 16\% and 20\%, respectively, in sHepG2 cells (Figure 6B-D). 

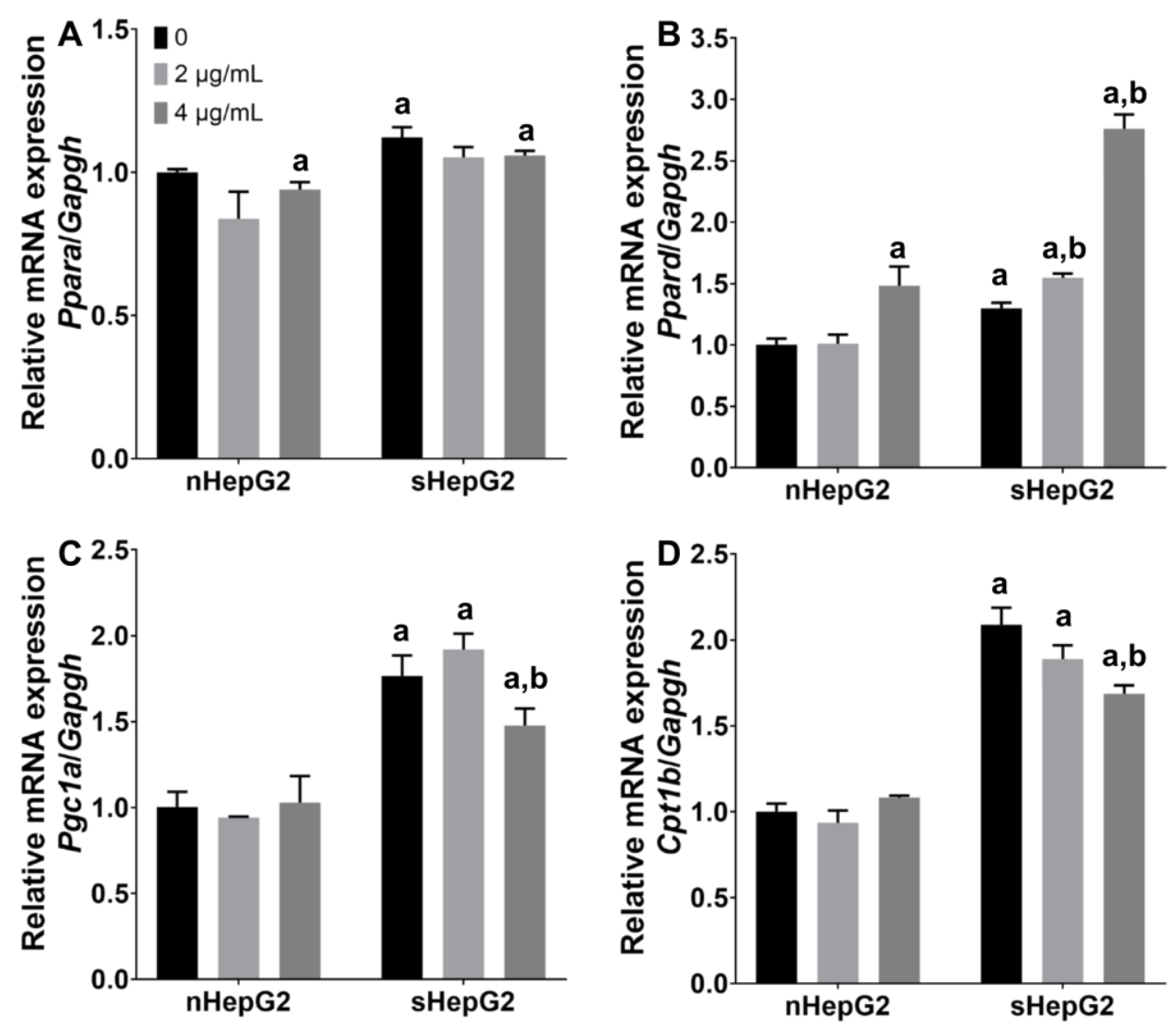

Figure 6. Expressions of FAO-related genes in nHepG2 and sHepG2 cells in response to Ag NP exposure. (A-D) Relative expressions of Ppara (A), Ppard (B), Pgc1a (C), and Cpt1b (D) in nHepG2 and sHepG2 cells exposed to 0,2 , and $4 \mu \mathrm{g} / \mathrm{mL} \mathrm{Ag} \mathrm{NPs} \mathrm{for} 24 \mathrm{~h}$. Data are shown as means \pm s.d., $\mathrm{n}=3$. ${ }^{\mathrm{a}} p<0.05$, compared with vehicle control of $\mathrm{nHepG} 2$ cells. ${ }^{\mathrm{b}} p<0.05$, compared with vehicle control of sHepG2 cells.

\subsection{Higher Accumulation of MNPs in sHepG2 Than in nHepG2}

At non-lethal dose of $4 \mu \mathrm{g} / \mathrm{mL}$, MNPs showed higher accumulation in sHepG2 cells in comparison with that in nHepG2 cells. The amounts of $\mathrm{Ag} \mathrm{NPs}, \mathrm{ZrO}_{2} \mathrm{NPs}, \mathrm{sTiO}_{2} \mathrm{NPs}$, and $1 \mathrm{TiO}_{2}$ NPs in sHepG2 were 2.8-, 1.9-, 1.4-, and 1.3-fold those in nHepG2 after the cells were incubated with these NPs for $24 \mathrm{~h}$ (Figure 7A). Meanwhile, neither the removal of OA from culture medium for sHepG2 cells nor the supplement of OA in medium for nHepG2 cells significantly shifted the accumulation of $\mathrm{Ag} \mathrm{NPs}$ and $\mathrm{sTiO}_{2} \mathrm{NPs}$ in these two cells (Figure 7B). These results demonstrate that it is the steatotic status but not the presence of OA that contributes to the higher accumulation of MNPs in sHepG2 than in nHepG2. 


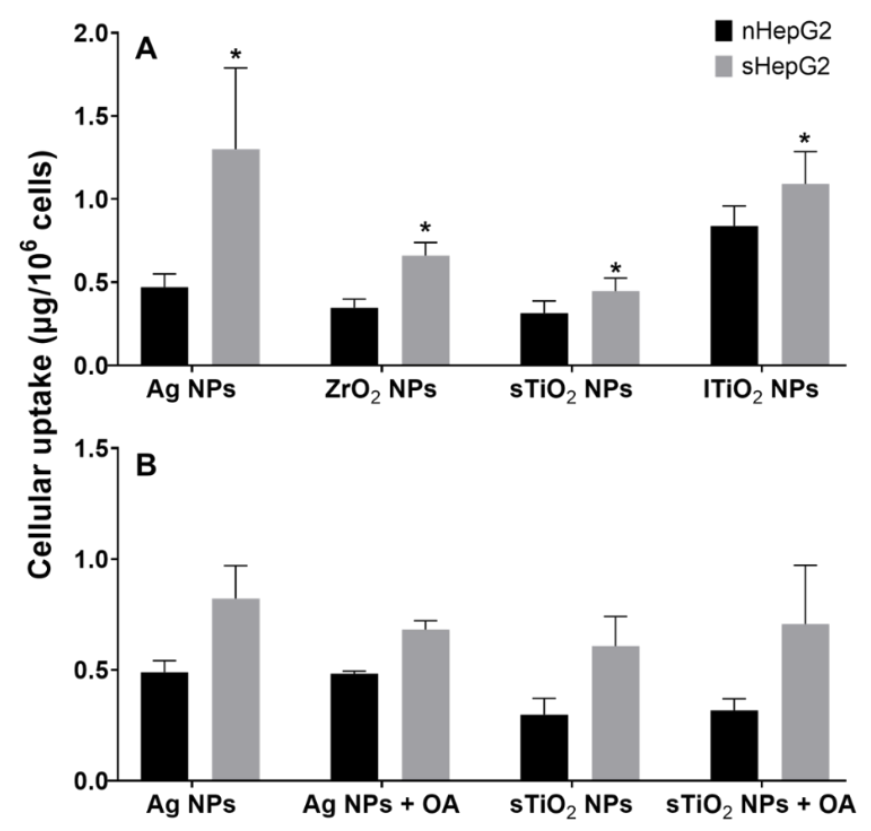

Figure 7. Differential cellular uptake of MNPs by nHepG2 and sHepG2. (A) Amounts of NPs in nHepG2 and sHepG2 cells after a 24-h incubation with $4 \mu \mathrm{g} / \mathrm{mL} \mathrm{Ag} \mathrm{NPs}, \mathrm{ZrO}_{2} \mathrm{NPs} \mathrm{sTiO}_{2} \mathrm{NPs}_{\text {or }}$ $1 \mathrm{TiO}_{2}$ NPs. (B) Cell uptake of NPs by nHepG2 and sHepG2 cells following the treatments with Ag $\mathrm{NPs}$ or $\mathrm{sTiO}_{2} \mathrm{NPs}$ for $3 \mathrm{~h}$ with/without the supplement of OA. Data were shown as means \pm s.d., $\mathrm{n}=3$. ${ }^{*} p<0.05$, compared with the amounts of NPs in nHepG2 cells with the same treatment.

\section{Discussion}

Liver toxicity is a pivotal concern for risk assessment of environmentally exposed MNPs, as the liver is the major organ where MNPs are deposited and metabolized. In healthy adult rodents, MNP exposure caused hepatic inflammation, oxidative stress, DNA damage, and hepatocyte apoptosis and/or necrosis [34-36]. The above adverse outcomes in response to MNP exposure may be further aggravated in rodent models of NAFLD [13], suggesting the susceptibility of NAFLD individuals to MNPs. Additionally, MNPs aggravated hepatocyte steatosis in NAFLD animal models [16,17]. Hepatic inflammation is a main driver of liver injury, accelerating the transformation of NAFLD from hepatic steatosis to steatohepatitis [37]. Meanwhile, it plays a critical role in regulating the lipid metabolism in hepatocytes. For example, pro-inflammatory cytokine tumor necrosis factor $\alpha(\mathrm{TNF}-\alpha)$ disturbed the metabolism of hepatic fatty acid, contributing to the pathogenesis of hepatic steatosis $[38,39]$. While the induction of hepatic inflammation, as indicated by the increased production of pro-inflammatory cytokines such as TNF- $\alpha$, interleukin-6 (IL-6), and IL- $1 \beta$, is one of the most common toxic outcomes of MNPs in both healthy and NAFLD animals [21], the susceptibility of steatotic hepatocytes to direct MNP exposures, especially in regulating the metabolic activity of intracellular lipids, remains to be elucidated. In the present work, the susceptibility of steatotic hepatocytes to four MNPs with different components and particle sizes was first determined in vitro using an OA-induced steatotic HepG2 cell model. Despite the particle size- and component-dependent cytotoxicity of these MNPs to both nHepG2 and sHepG2 cells, MNPs were more cytotoxic to sHepG2 than to nHepG2 (Figure 3), suggesting the susceptibility of steatotic hepatocytes in cytotoxicity to direct MNP exposure.

Induction of oxidative stress is one of the most well-recognized toxic mechanisms of nanosized particles [40]. The Kelch-like ECH-associated protein 1 (Keap1)/NF-E2related factor 2 (Nrf2)/ARE signaling system is the main antioxidant mechanism against even the lowest level of NP-triggered oxidative stress [41]. The repressor protein, Keap1, acts as a sensor of intracellular oxidative stress, dissociating the transcription factor Nrf2 from the Keap1-Nrf2 complex in response to oxidative stress, and the released Nrf2 then 
regulates the induction of gene encoding antioxidant proteins via ARE [42,43]. Thus, the ARE reporter has been applied as the most sensitive strategy for measuring the NPinduced oxidative stress response in cells [44]. Using an ARE reporter HepG2 cell line, we compared the induction of oxidative stress in nHepG2 and sHepG2 cells in response to MNP exposure. Treatments with MNPs upregulated the expression of the ARE reporter only in sHepG2 cells (Figure 4), suggesting that the induction of oxidative stress was involved in the susceptibility of steatotic hepatocytes in cytotoxicity to MNP exposure. Previously, the induction of oxidative stress in response to MNP exposure was associated with the inhibition of various detoxification enzymes. One great example is that the inhibition of antioxidant defense systems was shown to be responsible for the gold NPinduced oxidative stress in various human cells $[45,46]$. Thus, the potential role of the regulatory effects of MNPs on the differential induction of oxidative stress in nHepG2 and sHepG2 cells remains to be elucidated.

The pathogenesis of NAFLD is complex and multifactorial. Peroxisome proliferatoractivated receptors (PPARs) are a class of nuclear receptors that have been proven to play critical roles in regulating the metabolism of glucose and lipids, contributing to the development and progression of NAFLD [47]. Among the three PPAR isoforms existing in mammals, both PPAR $\alpha$ and PPAR $\delta$ have high expression in the liver, while PPAR $\gamma$ is highly expressed in adipose tissue [48]. In response to Ag NP exposures, our previous study has shown that the downregulated expression of Ppard, and its co-activator Pgc1a and target genes contributed to the aggravated hepatic steatosis in overweight mice [17]. However, the question of whether the increased accumulation of lipids in hepatocytes is caused by the internalized Ag NPs in hepatocytes remains to be answered. In the present work, Ag NP exposure showed little effect on the expression of Ppara. Meanwhile, treatments with Ag NPs upregulated the expression of Ppard but downregulated its co-activator Pgc1a and target gene Cpt1b (Figure 6). Despite the disagreement of the Ag NP-regulated expression of Ppard in vitro and in vivo, the inhibitory potential of Ag NP exposure on the process of FAO is suggested to be the same, as Ppard and its co-activator Pgc1a together regulate the process of FAO [49]. In contrast, significantly increased accumulation of lipids was not detected in either nHepG2 or sHepG2 cells in response to Ag NP exposure (Figure 5), probably because an exposure time of $24 \mathrm{~h}$ was too short.

The intracellular amounts of MNPs increased with the exposure doses, resulting in dose-dependent cytotoxicity of various MNPs, which has been well-recognized in previous studies [50-52]. Thus, the MNP-induced cytotoxicity is primarily determined by the intracellular dose of MNPs. In this work, we found that both Ag NPs and sTiO2 NPs had much higher accumulation in sHepG2 cells than in nHepG2 cells (Figure 7a), which was suggested to be responsible for the susceptibility of sHepG2 cells in response to MNP exposure. Even though we excluded the contribution of OA on the differential internalization of MNPs in nHepG2 and sHepG2 cells (Figure 7b), the underlying mechanisms of the enhanced accumulation of MNPs in steatotic hepatocytes remain to be elucidated from how the steatotic status affects the internalization, subcellular localization, and excretion of MNPs in steatotic hepatocytes.

\section{Materials and Methods}

\subsection{Preparation of $M N P S$}

$\mathrm{TiO}_{2} \mathrm{NPs}$ of two sizes, Ag NPs and $\mathrm{ZrO}_{2} \mathrm{NPs}$, were purchased from Shanghai Macklin Biochemical Co., Ltd. (Shanghai, China), Xuzhou Jiechuang New Material Technology Co., Ltd. (Guangzhou, China), and Yi Fu Co., Ltd. (Shanghai, China), respectively. The morphology and particle size of NPs were analyzed by transmission electron microscope (TEM, JEM-2100F, Jeol, Japan). The hydrodynamic size and the zeta potential of NPs in deionized water or cell culture medium supplemented with $10 \%$ fetal bovine serum (FBS, ExCell Bio, Shanghai, China) were measured using the NanoBrook Omni Particle Analyzer (Brookhaven Instruments, New York, NY, USA). The NPs were dispersed in aqueous solutions and sonicated for $30 \mathrm{~min}$ before administration. 


\subsection{Cell Culture and Steatotic Hepatocyte Modeling}

Human hepatocellular carcinoma HepG2 cells kindly provided by Stem Cell Bank, Chinee Academy of Sciences were cultured in minimum essential medium (MEM, HyClone, UT, USA) containing 10\% FBS (ExCell Bio, Shanghai, China), 1\% Penicillin-Streptomycin Solution (HyClone, UT, USA), $1 \%$ Sodium Pyruvate (Gibco, New York, NY, USA), $1 \%$ MEM Non-Essential Amino Acids (Gibco, New York, NY, USA), and 1\% GlutaMAXTM-1 (Gibco, New York, NY, USA). The cells were maintained in a 95\% humidity and $5 \% \mathrm{CO}_{2}$ incubator at $37^{\circ} \mathrm{C}$ for cultivation. For steatotic hepatocyte modeling, HepG2 cells were seeded in a 12 -well plate $(60,000$ cells per well). After incubation for $24 \mathrm{~h}$, cell culture medium in each well were replaced with fresh culture medium containing $0,0.1,0.5,1.0,1.5$, or $2.0 \mathrm{mM}$ oleic acid (OA) for another $24 \mathrm{~h}$. Cells were washed with PBS three times, stained with oil red O, and analyzed using ECLIPSE Ti2-U Inverted Microscope System (Nikon Instruments Inc., Tokyo, Japan). Real-time growth status of cells in response to OA treatments $(0,0.1,0.5,1.0$, and $2.0 \mathrm{mM}$ ) was determined using an $\times$ CELLigence real-time cell analysis system (OLS OMNI Life Science GmbH \& Co KG, Bremen, Germany) and reflected as a normalized cell index.

\subsection{Cell Viability Assay}

Cells were seeded in 96-well plates (6000 cells per well). After $24 \mathrm{~h}$ incubation, the cells were treated with $0.5 \mathrm{mM}$ OA for $24 \mathrm{~h}$ for steatotic hepatocyte modeling and then treated with NPs of various concentrations (with the presence of $0.5 \mathrm{mM} \mathrm{OA}$ ) for another $24 \mathrm{~h}$. The viability of HepG2 cells was measured using commercialized CellTiter-Lumi ${ }^{\mathrm{TM}}$ Luminescent Cell Viability Assay Kit (Beyotime Biotechnology, Shanghai, China) on a Synergy HTX Multi-Mode Reader (BioTek, Winooski, VT, USA).

\subsection{Antioxidant Responsive Element (ARE) Reporter Gene Assay}

ARE firefly luciferase vectors (pGL4.37[luc2P/ARE/Hygro]) were purchased from Promega (Beijing) Biotech Co., Ltd. (Beijing, China). The ARE reporter cell line was prepared by transfecting the pGL4.37[luc2P/ARE/Hygro] vectors into HepG2 cells using Lipofectamine ${ }^{\circledR}$ LTX reagent (Thermo Fisher Scientific China Co., Ltd., Shanghai, China). Resistant colonies were selected using $0.45 \mathrm{mg} / \mathrm{mL}$ hygromycin. Stable transfected cells were maintained in MEM supplemented with 10\% FBS, 1\% Penicillin-Streptomycin Solution, $1 \%$ Sodium Pyruvate, 1\% MEM Non-Essential Amino Acids, $1 \%$ GlutaMAXTM- 1 and $0.2 \mathrm{mg} / \mathrm{mL}$ hygromycin. To determine the luciferase activity induced by NPs, the ARE reporter cells were treated with OA for $24 \mathrm{~h}$ for steatotic hepatocyte modeling and with NPs for another $24 \mathrm{~h}$. Following incubation with Bright-Lumi ${ }^{\mathrm{TM}}$ II Firefly Luciferase Assay Kit reagent (Beyotime Biotechnology, Shanghai, China), luciferase activity was measured on a Synergy HTX Multi-Mode Reader (BioTek, Winooski, VT, USA).

\subsection{Real-Time Quantitative Reverse Transcription PCR ( $q R T-P C R$ )}

Total RNA of HepG2 cells treated with $4 \mu \mathrm{g} / \mathrm{mL}$ NPs for $24 \mathrm{~h}$ was extracted with Trizol reagent (Ambion, Carlsbad, CA, USA). The concentration and quality of RNA was determined using a NanoDrop One spectrophotometer (Thermo Scientific, Waltham, MA, USA). RNA to cDNA were reversely transcribed using PrimeScript ${ }^{\mathrm{TM}}$ RT Master Mix (Takara Bio Inc., Shiga, Japan). TB Green ${ }^{\mathrm{TM}}$ Premix Ex Taq ${ }^{\mathrm{TM}}$ II (Takara Bio Inc., Shiga, Japan) was used to perform quantitative PCR on a LightCycler ${ }^{\circledR} 96$ Instrument (Roche Molecular Systems, Inc., Pleasanton, CA, USA). The relative expression of genes was quantified using the $2^{-\Delta \Delta C T}$ method [53]. Primers (Table 1) used in this study were synthesized by Sangon Biotech (Shanghai, China). 
Table 1. Primers used for qRT-PCR.

\begin{tabular}{ccc}
\hline Genes & \multicolumn{1}{c}{ Sequence $\mathbf{( 5}^{\prime} \mathbf{- 3}^{\prime} \mathbf{)}$} & Size (bp) \\
\hline GAPDH & $\begin{array}{c}\text { Forward: GCCTCAAGATCATCAGCAATG } \\
\text { Reverse: CCTCCACGATACCAAAGTTGTC } \\
\text { Forward: CCAGTATTTAGGAAGCTGTCC } \\
\text { Peverse: TGAAAGCGTGTCCGTGAT }\end{array}$ & 90 \\
PPARD & $\begin{array}{c}\text { Forward: CTACGGTGTTCATGCATGTGAGG } \\
\text { Reverse: GCACTTCTGGAAGCGGCAGTA } \\
\text { Forward: AATTGAAGAGCGCCGTGT } \\
\text { PGC1A }\end{array}$ & 145 \\
CPT1B & $\begin{array}{c}\text { Foverse: AACCATAGCTGTCTCCATC } \\
\text { Forward: ACTGCTACAACAGGTGGTT }\end{array}$ & 140 \\
& & 76 \\
\hline
\end{tabular}

\subsection{Total Cholesterol and Triacylglycerol Levels}

Logarithmic growth cells were seeded into 12-well plates. After incubation for $24 \mathrm{~h}$, the normal cell culture medium was replaced by the cell culture medium with/without $0.5 \mathrm{mM}$ OA for cell modeling for another $24 \mathrm{~h}$. Then, the cells were treated with metalbased nanoparticles $24 \mathrm{~h}$. The cells were collected, and the total cholesterol (T-CHO) and triacylglycerol (TG) levels of HepG2 cells after various treatments were determined by T-CHO/TG Assay Kit (Nanjing Jiancheng Bioengineering Institute, Nanjing, China).

\subsection{Cellular Uptake}

HepG2 cells were seeded in 12-well plates at a density of 60,000 cells per well. After a $24 \mathrm{~h}$ incubation and a $24 \mathrm{~h}$ steatotic hepatocyte modeling, the cells were treated with $4 \mu \mathrm{g} / \mathrm{mL} \mathrm{NPs}$ for another $24 \mathrm{~h}$. Cells were then washed three times with PBS, detached by $0.25 \%$ trypsin-EDTA solution (Gibco, New York, NY, USA), collected, and counted. The collected cells were dissolved with nitric acid and analyzed using the Inductively Coupled Plasma Mass Spectrometry (ICP-MS, Agilent 7900, Agilent Technologies, Inc., Santa Clara, CA, USA). To explore the effect of OA on the cellular uptake of NPs, cells were exposed to $4 \mu \mathrm{g} / \mathrm{mL} \mathrm{Ag} \mathrm{NPs} \mathrm{or} \mathrm{sTiO}_{2} \mathrm{NPs}$ for $3 \mathrm{~h}$ with/without the supplement of OA, and the intracellular amounts of NPs were determined using the above methods.

\section{Conclusions}

Using an OA-induced steatotic HepG2 cell model, we found that the steatotic hepatocytes were more sensitive to MNP exposures than the non-steatotic in both cytotoxicity and induction of oxidative stress. MNPs showed the potential of perturbing the process of FAO at extremely low doses only in steatotic hepatocytes. The susceptibility of steatotic hepatocytes in response to MNP exposure was in association with the higher cellular accumulation of MNPs, suggesting the necessity and urgency to take the intracellular exposure dose into consideration in the health risk assessment of environmentally exposed MNPs.

Supplementary Materials: The Supplementary Materials are available online at https:/ /www.mdpi. com/article/10.3390/ijms222312643/s1.

Author Contributions: Conceptualization, J.J. and X.Z.; methodology, X.Z. and Y.W.; software, J.J., X.Z., and C.L.; validation, W.W. and R.Z.; formal analysis, X.Z.; investigation, X.Z. and Y.W.; writingoriginal draft preparation, X.Z.; writing-review and editing, J.J., C.L., and B.Y.; visualization, X.Z.; supervision, J.J. and B.Y.; project administration, J.J.; funding acquisition, J.J. and B.Y. All authors have read and agreed to the published version of the manuscript.

Funding: This research was funded by the National Natural Science Foundation of China, grant numbers 21906035 and 22036002; the Basic and Applied Basic Research Foundation of Guangzhou, China, grant number 202102020399; and the introduced innovative R\&D team project under the "The Pearl River Talent Recruitment Program” of Guangdong Province, grant number 2019ZT08L387.

Institutional Review Board Statement: Not applicable. 
Informed Consent Statement: Not applicable.

Conflicts of Interest: The authors declare no conflict of interest.

\section{References}

1. Hansen, S.F.; Hansen, O.F.H.; Nielsen, M.B. Advances and challenges towards consumerization of nanomaterials. Nat. Nanotechnol. 2020, 15, 964-965. [CrossRef] [PubMed]

2. Lowry, G.V.; Avellan, A.; Gilbertson, L.M. Opportunities and challenges for nanotechnology in the agri-tech revolution. Nat. Nanotechnol. 2019, 14, 517-522. [CrossRef]

3. Weintraub, K. Biomedicine: The new gold standard. Nature 2013, 495, S14-S16. [CrossRef] [PubMed]

4. Zou, Y.; Wang, X.; Khan, A.; Wang, P.; Liu, Y.; Alsaedi, A.; Hayat, T.; Wang, X. Environmental Remediation and Application of Nanoscale Zero-Valent Iron and Its Composites for the Removal of Heavy Metal Ions: A Review. Environ. Sci. Technol. 2016, 50, 7290-7304. [CrossRef]

5. Nanodatabase. Consumer Products. Available online: https://nanodb.dk/en/ (accessed on 1 August 2021).

6. Zhang, Y.; Bai, Y.; Jia, J.; Gao, N.; Li, Y.; Zhang, R.; Jiang, G.; Yan, B. Perturbation of physiological systems by nanoparticles. Chem. Soc. Rev. 2014, 43, 3762-3809. [CrossRef]

7. Sengul, A.B.; Asmatulu, E. Toxicity of metal and metal oxide nanoparticles: A review. Environ. Chem. Lett. 2020, 18, 1659-1683. [CrossRef]

8. Li, Y.; Zhang, Y.; Yan, B. Nanotoxicity Overview: Nano-Threat to Susceptible Populations. Int. J. Mol. Sci. 2014, 15, 3671-3697. [CrossRef]

9. Jia, J.; Jiang, C.; Yan, B. Potential nanotoxicity in susceptible populations: Insight from investigation of mouse models. Chin. Sci. Bull. 2017, 62, 2749-2757. [CrossRef]

10. Wang, Z.; Zhang, C.; Huang, F.; Liu, X.; Wang, Z.; Yan, B. Breakthrough of $\mathrm{ZrO}_{2}$ nanoparticles into fetal brains depends on developmental stage of maternal placental barrier and fetal blood-brain-barrier. J. Hazard. Mater. 2021, 402, 123563. [CrossRef]

11. Boey, A.; Ho, H.K. All Roads Lead to the Liver: Metal Nanoparticles and Their Implications for Liver Health. Small 2020, 16, 2000153. [CrossRef]

12. Bartneck, M.; Ritz, T.; Keul, H.A.; Wambach, M.; Bornemann, J.; Gbureck, U.; Ehling, J.; Lammers, T.; Heymann, F.; Gassler, N.; et al. Peptide-Functionalized Gold Nanorods Increase Liver Injury in Hepatitis. ACS Nano 2012, 6, 8767-8777. [CrossRef]

13. Hwang, J.H.; Kim, S.J.; Kim, Y.-H.; Noh, J.-R.; Gang, G.-T.; Chung, B.H.; Song, N.W.; Lee, C.-H. Susceptibility to gold nanoparticleinduced hepatotoxicity is enhanced in a mouse model of nonalcoholic steatohepatitis. Toxicology 2012, 294, 27-35. [CrossRef] [PubMed]

14. Younossi, Z.M.; Koenig, A.B.; Abdelatif, D.; Fazel, Y.; Henry, L.; Wymer, M. Global epidemiology of nonalcoholic fatty liver disease-Meta-analytic assessment of prevalence, incidence, and outcomes. Hepatology 2016, 64, 73-84. [CrossRef]

15. Brunt, E.M.; Wong, V.W.S.; Nobili, V.; Day, C.P.; Sookoian, S.; Maher, J.J.; Bugianesi, E.; Sirlin, C.B.; Neuschwander-Tetri, B.A.; Rinella, M.E. Nonalcoholic fatty liver disease. Nat. Rev. Dis. Primers 2015, 1, 15080. [CrossRef] [PubMed]

16. Zhu, M.; Chen, H.; Zhou, S.; Zheng, L.; Li, X.; Chu, R.; Chen, W.; Wang, B.; Wang, M.; Chai, Z.; et al. Iron oxide nanoparticles aggravate hepatic steatosis and liver injury in nonalcoholic fatty liver disease through BMP-SMAD-mediated hepatic iron overload. Nanotoxicology 2021, 15, 761-778. [CrossRef]

17. Jia, J.; Li, F.; Zhou, H.; Bai, Y.; Liu, S.; Jiang, Y.; Jiang, G.; Yan, B. Oral Exposure to Silver Nanoparticles or Silver Ions May Aggravate Fatty Liver Disease in Overweight Mice. Environ. Sci. Technol. 2017, 51, 9334-9343. [CrossRef] [PubMed]

18. Medina-Reyes, E.I.; Delgado-Buenrostro, N.L.; Díaz-Urbina, D.; Rodríguez-Ibarra, C.; Déciga-Alcaraz, A.; González, M.I.; Reyes, J.L.; Villamar-Duque, T.E.; Flores-Sánchez, M.L.O.; Hernández-Pando, R.; et al. Food-grade titanium dioxide (E171) induces anxiety, adenomas in colon and goblet cells hyperplasia in a regular diet model and microvesicular steatosis in a high fat diet model. Food Chem. Toxicol. 2020, 146, 111786. [CrossRef]

19. Jia, J.; Li, F.; Zhai, S.; Zhou, H.; Liu, S.; Jiang, G.; Yan, B. Susceptibility of Overweight Mice to Liver Injury as a Result of the ZnO Nanoparticle-Enhanced Liver Deposition of Pb2+. Environ. Sci. Technol. 2017, 51, 1775-1784. [CrossRef]

20. Zhou, Z.; Xu, M.-J.; Gao, B. Hepatocytes: A key cell type for innate immunity. Cell. Mol. Immunol. 2016, 13, 301-315. [CrossRef]

21. Yao, Y.; Zang, Y.; Qu, J.; Tang, M.; Zhang, T. The Toxicity Of Metallic Nanoparticles On Liver: The Subcellular Damages, Mechanisms, And Outcomes. Int. J. Nanomed. 2019, 14, 8787-8804. [CrossRef]

22. Kung, M.-L.; Hsieh, S.-L.; Wu, C.-C.; Chu, T.-H.; Lin, Y.-C.; Yeh, B.-W.; Hsieh, S. Enhanced reactive oxygen species overexpression by $\mathrm{CuO}$ nanoparticles in poorly differentiated hepatocellular carcinoma cells. Nanoscale 2015, 7, 1820-1829. [CrossRef]

23. Ali, D.; Alarifi, S.; Alkahtani, S.; Almeer, R.S. Silver-doped graphene oxide nanocomposite triggers cytotoxicity and apoptosis in human hepatic normal and carcinoma cells. Int. J. Nanomed. 2018, 13, 5685-5699. [CrossRef]

24. Vidyashankar, S.; Sandeep Varma, R.; Patki, P.S. Quercetin ameliorate insulin resistance and up-regulates cellular antioxidants during oleic acid induced hepatic steatosis in HepG2 cells. Toxicol. In Vitro 2013, 27, 945-953. [CrossRef]

25. Janorkar, A.V.; King, K.R.; Megeed, Z.; Yarmush, M.L. Development of an in vitro cell culture model of hepatic steatosis using hepatocyte-derived reporter cells. Biotechnol. Bioeng. 2009, 102, 1466-1474. [CrossRef]

26. Cui, W.; Chen, S.L.; Hu, K.-Q. Quantification and mechanisms of oleic acid-induced steatosis in HepG2 cells. Am. J. Transl. Res. 2010, 2, 95-104. [PubMed] 
27. Puzyn, T.; Rasulev, B.; Gajewicz, A.; Hu, X.; Dasari, T.P.; Michalkova, A.; Hwang, H.-M.; Toropov, A.; Leszczynska, D.; Leszczynski, J. Using nano-QSAR to predict the cytotoxicity of metal oxide nanoparticles. Nat. Nanotechnol. 2011, 6, 175-178. [CrossRef] [PubMed]

28. Park, M.V.D.Z.; Neigh, A.M.; Vermeulen, J.P.; de la Fonteyne, L.J.J.; Verharen, H.W.; Briedé, J.J.; van Loveren, H.; de Jong, W.H. The effect of particle size on the cytotoxicity, inflammation, developmental toxicity and genotoxicity of silver nanoparticles. Biomaterials 2011, 32, 9810-9817. [CrossRef]

29. Reddy, C.V.; Reddy, I.N.; Ravindranadh, K.; Reddy, K.R.; Shetti, N.P.; Kim, D.; Shim, J.; Aminabhavi, T.M. Copper-doped ZrO 2 nanoparticles as high-performance catalysts for efficient removal of toxic organic pollutants and stable solar water oxidation. $J$. Environ. Manag. 2020, 260, 110088. [CrossRef]

30. Zhang, Q.; Bolisetty, S.; Cao, Y.; Handschin, S.; Adamcik, J.; Peng, Q.; Mezzenga, R. Selective and Efficient Removal of Fluoride from Water: In Situ Engineered Amyloid Fibril/ZrO 2 Hybrid Membranes. Angew. Chem. Int. Ed. 2019, 58, 6012-6016. [CrossRef] [PubMed]

31. Abbott Chalew, T.E.; Schwab, K.J. Toxicity of commercially available engineered nanoparticles to Caco-2 and SW480 human intestinal epithelial cells. Cell Biol. Toxicol. 2013, 29, 101-116. [CrossRef]

32. Chen, Y.; Xu, M.; Zhang, J.; Ma, J.; Gao, M.; Zhang, Z.; Xu, Y.; Liu, S. Genome-Wide DNA Methylation Variations upon Exposure to Engineered Nanomaterials and Their Implications in Nanosafety Assessment. Adv. Mater. 2017, 29, 1604580. [CrossRef]

33. Bai, X.; Wang, S.; Yan, X.; Zhou, H.; Zhan, J.; Liu, S.; Sharma, V.K.; Jiang, G.; Zhu, H.; Yan, B. Regulation of Cell Uptake and Cytotoxicity by Nanoparticle Core under the Controlled Shape, Size, and Surface Chemistries. ACS Nano 2020, 14, 289-302. [CrossRef]

34. Jarrar, Y.; Al-Doaiss, A.; Alfaifi, M.; Shati, A.; Al-Kahtani, M.; Jarrar, B. The influence of five metallic nanoparticles on the expression of major drug-metabolizing enzyme genes with correlation of inflammation in mouse livers. Environ. Toxicol. Pharmacol. 2020, 80, 103449. [CrossRef] [PubMed]

35. Chen, T.-Y.; Chen, M.-R.; Liu, S.-W.; Lin, J.-Y.; Yang, Y.-T.; Huang, H.-Y.; Chen, J.-K.; Yang, C.-S.; Lin, K.M.-C. Assessment of Polyethylene Glycol-Coated Gold Nanoparticle Toxicity and Inflammation In Vivo Using NF-кB Reporter Mice. Int. J. Mol. Sci. 2020, 21, 8158. [CrossRef]

36. Shukla, R.K.; Kumar, A.; Vallabani, N.V.S.; Pandey, A.K.; Dhawan, A. Titanium dioxide nanoparticle-induced oxidative stress triggers DNA damage and hepatic injury in mice. Nanomedicine 2014, 9, 1423-1434. [CrossRef] [PubMed]

37. Schuster, S.; Cabrera, D.; Arrese, M.; Feldstein, A.E. Triggering and resolution of inflammation in NASH. Nat. Rev. Gastroenterol. Hepatol. 2018, 15, 349-364. [CrossRef]

38. Yang, R.; Guan, M.-J.; Zhao, N.; Li, M.-J.; Zeng, T. Roles of extrahepatic lipolysis and the disturbance of hepatic fatty acid metabolism in TNF- $\alpha$-induced hepatic steatosis. Toxicology 2019, 411, 172-180. [CrossRef] [PubMed]

39. Endo, M.; Masaki, T.; Seike, M.; Yoshimatsu, H. TNF- $\alpha$ Induces Hepatic Steatosis in Mice by Enhancing Gene Expression of Sterol Regulatory Element Binding Protein-1c (SREBP-1c). Exp. Biol. Med. 2007, 232, 614-621. [CrossRef]

40. Horie, M.; Tabei, Y. Role of oxidative stress in nanoparticles toxicity. Free Radic. Res. 2020, 55, 331-342. [CrossRef]

41. Nel, A.; Xia, T.; Mädler, L.; Li, N. Toxic Potential of Materials at the Nanolevel. Science 2006, 311, 622-627. [CrossRef]

42. Makoto, K.; Masayuki, Y. Molecular Mechanisms Activating the Nrf2-Keap1 Pathway of Antioxidant Gene Regulation. Antioxid. Redox Sign. 2005, 7, 385-394. [CrossRef]

43. Kansanen, E.; Kuosmanen, S.M.; Leinonen, H.; Levonen, A.-L. The Keap1-Nrf2 pathway: Mechanisms of activation and dysregulation in cancer. Redox Biol. 2013, 1, 45-49. [CrossRef]

44. Le, T.C.; Yin, H.; Chen, R.; Chen, Y.; Zhao, L.; Casey, P.S.; Chen, C.; Winkler, D.A. An Experimental and Computational Approach to the Development of ZnO Nanoparticles that are Safe by Design. Small 2016, 12, 3568-3577. [CrossRef] [PubMed]

45. Penninckx, S.; Heuskin, A.-C.; Michiels, C.; Lucas, S. Gold Nanoparticles as a Potent Radiosensitizer: A Transdisciplinary Approach from Physics to Patient. Cancers 2020, 12, 2021. [CrossRef]

46. Penninckx, S.; Heuskin, A.C.; Michiels, C.; Lucas, S. The role of thioredoxin reductase in gold nanoparticle radiosensitization effects. Nanomedicine (Lond.) 2018, 13, 2917-2937. [CrossRef]

47. Liss, K.H.H.; Finck, B.N. PPARs and nonalcoholic fatty liver disease. Biochimie 2017, 136, 65-74. [CrossRef]

48. Tailleux, A.; Wouters, K.; Staels, B. Roles of PPARs in NAFLD: Potential therapeutic targets. Biochim. Biophys. Acta 2012, 1821, 809-818. [CrossRef]

49. Finck, B.N.; Kelly, D.P. Peroxisome proliferator-activated receptor gamma coactivator-1 (PGC-1) regulatory cascade in cardiac physiology and disease. Circulation 2007, 115, 2540-2548. [CrossRef]

50. Miethling-Graff, R.; Rumpker, R.; Richter, M.; Verano-Braga, T.; Kjeldsen, F.; Brewer, J.; Hoyland, J.; Rubahn, H.-G.; Erdmann, H. Exposure to silver nanoparticles induces size- and dose-dependent oxidative stress and cytotoxicity in human colon carcinoma cells. Toxicol. In Vitro 2014, 28, 1280-1289. [CrossRef] [PubMed]

51. Ahamed, M.; Akhtar, M.J.; Khan, M.A.M.; Alrokayan, S.A.; Alhadlaq, H.A. Oxidative stress mediated cytotoxicity and apoptosis response of bismuth oxide $\left(\mathrm{Bi}_{2} \mathrm{O}_{3}\right)$ nanoparticles in human breast cancer (MCF-7) cells. Chemosphere 2019, 216, 823-831. [CrossRef]

52. Asani, S.C.; Umrani, R.D.; Paknikar, K.M. Differential dose-dependent effects of zinc oxide nanoparticles on oxidative stressmediated pancreatic $\beta$-cell death. Nanomedicine 2017, 12, 745-759. [CrossRef] [PubMed]

53. Livak, K.J.; Schmittgen, T.D. Analysis of Relative Gene Expression Data Using Real-Time Quantitative PCR and the $2^{-\Delta \Delta C T}$ Method. Methods 2001, 25, 402-408. [CrossRef] [PubMed] 